\title{
Climate change, parasites and shifting boundaries
}

\author{
Lydden Polley $^{1 *}$, Eric Hoberg ${ }^{2}$, Susan Kutz ${ }^{3}$ \\ From Parasite infections of domestic animals in the Nordic countries - emerging threats and challenges. \\ The 22nd Symposium of the Nordic Committee for Veterinary Scientific Cooperation (NKVet) \\ Helsinki, Finland. 7-9 September 2008
}

\section{Background}

Around the world the three major components of climate change already evident and escalating in magnitude and significance are; 1 ) warming; 2) altered patterns of precipitation; and 3) an increased incidence of extreme climatic events [1]. For the structure and function of ecosystems, impacts of climate change vary with place and with time, and among the key outcomes are shifting boundaries for many components and processes within the systems. Among these components are pathogens and infectious diseases, including those caused by helminth, arthropod and protozoan parasites in people, domestic animals, and wildlife [2].

For host-parasite assemblages, boundaries potentially vulnerable to climate change include those for spatial and temporal distributions of hosts and parasites, for parasite survival and development in hosts and in the environment, for risks of transmission to hosts at critical points in parasite webs, and for health effects on hosts, including the emergence or resurgence of disease. The often complex and obscure linkages and inter-relationships among components of an ecosystem, coupled with the uncertain and variable trajectories for climate change, make it difficult to identify all these vulnerabilities, particularly in the medium to long term. Also, faced with non-overwhelming "stress" most ecosystems display a degree of resilience that may mitigate some of the consequences of climate change $[3,4]$, and in some circumstances the significance of parasites remains essentially unchanged. Finally, some recent shifts in disease occurrence that intuition might suggest are associated with climate change have proved likely to be wholly or partly the result of other factors $[5,6]$.

\footnotetext{
* Correspondence: Iydden.polley@usask.ca

${ }^{1}$ Department of Veterinary Microbiology, Western College of Veterinary Medicine, University of Saskatchewan, Saskatoon, Saskatchewan S7N 5B4, Canada

Full list of author information is available at the end of the article
}

The primary aim of this paper is to provide a framework for thinking about the critical potential connections between climate change, parasites, people, and wildlife in the circumpolar North, and between these host groups, climate change, parasites and domestic animals in other areas of the world.

\section{Approaches}

Much of the information currently available on climate change and infectious disease relates to people and is based on retrospective analyses of associations between components of climate involved in climate change and the occurrence of disease in human populations $[7,8]$. In other instances, features of parasite ecology have been linked to model-based scenarios for future climate change to generate medium to long-term projections for parasite and disease distribution and occurrence $[9,10]$. Underlying these approaches are observational and experimental studies in a range of systems exploring, on a more intimate scale, the relationships between climate and parasite, and sometimes host, ecology [11-13]. All these lines of enquiry are increasing understanding of the mechanisms generating boundary shifts for parasites and diseases resulting from climate change, and are assisting proper targeting of measures to minimize their impacts on human and animal health. Encouragingly, effective climate-based forecasting, developed decades ago for ruminant fascioliasis [14], is now a reality for some epidemic human malaria in Africa [15] and is being evaluated for other human parasitic diseases, for example human fascioliasis [16] and leishmaniasis [17] in South America. Exploration of the effects of climate change on infectious disease ecology presents many opportunities for valuable comparisons across pathogen and host groups, and across ecosystems.

Central to understanding these climate change-hostparasite linkages is the ability to detect and measure shifts in key features of parasites and hosts and to assemble data 
unequivocally establishing or refuting links to climate change. Given relevant meteorological data, although monitoring and surveillance of parasitic infections and diseases may be possible to some extent in people and domestic animals, even in remote areas with limited infrastructure, it is usually more difficult in wildlife [18]. A particular issue for this host group, especially in Arctic and the North and other relatively isolated areas, is the currently limited understanding of the parasite fauna, including species diversity and distribution, and its health significance, especially in the absence of obvious disease or mortality $[19,20]$. A recently initiated and very promising approach in northern Canada and elsewhere is to recruit, train and fund northerners, particularly harvesters who have frequent contact with wildlife, as health monitors. This program is greatly enhanced in the longer term where wildlife and wildlife health are introduced into curricula for schools in northern communities (see http:// www.ccwhc.ca/Sahtu/index.php).

\section{The fragile North}

The North is among areas of the world where climate change is already having significant and obvious effects and is impacting northerners and the animal and plant resources vital to their health and well-being $[21,22]$. For example, at risk on land are keystone wildlife species, including caribou, reindeer, moose, thinhorn sheep and muskoxen, waterfowl, and fish, together with berries and other foods of plant origin. In the surrounding oceans, polar bears, seals, walrus, seabirds and fish are all vulnerable. Among the elements of climate change threatening the health and sustainability of people and wildlife in the North, perhaps the most significant is warming, which is shifting boundaries for animals and plants [23], and for sea ice, permafrost, snow cover, and hydrology, as well as local and regional infrastructure [22]. Warming is also a cause of rising sea levels and the consequent erosion and flooding of coastal areas and disruption of coastal ecosystems and settlements [22].

People and animals that inhabit the North are beset by an array of helminth, arthropod and protozoan parasites. Most of these are restricted to one of the two host groups, but several - the zoonoses - are transmissible from animals to people, often through foods integral to traditional local cultures [18]. These zoonoses include (in North America) Trichinella, Anisakis, Diphyllobothrium, Echinococcus, and Toxoplasma, and perhaps Cryptosporidium and Giardia. All of these can cause obvious clinical disease in people, but not in everyone who is infected.

\section{Host and parasite vulnerabilities}

Many aspects of host and parasite ecology in the North and elsewhere have been identified as potentially vulnerable to climate change. Among possible consequences are boundary shifts that can alter the structure and function of host-parasite assemblages $[24,25]$. The speed and extent of these shifts vary with place and with time. For example, those linked to extreme climatic events may be rapid and localized, whereas those resulting from warming may be more gradual and widespread. For definitive and intermediate hosts, including arthropod vectors, these shifts include: 1) geographic distributions - expansion into new areas and/or loss from old areas and, in some cases, local to regional extinctions, together with shifts in migration routes; 2) faunal structure - qualitative changes in the composition of multi-species host communities, including shifts in opportunities for contacts between wildlife and domestic animals; 3 ) trophic linkages - including predator-prey relationships important for parasite transmission, especially for several zoonoses [26]; 4) phenology - especially the timing of breeding seasons and migrations, and the synchronization of the need for and availability of food; 5) level of nutrition - determined by the composition, availability, accessibility and quality of food and water; 6) health and wellbeing - including patterns of disease occurrence, and possible detrimental synergies between parasites, other infectious agents and other diseases; 7) host abundance - possibly affecting host density and thus parasite transmission dynamics; 8) behavioural patterns - influencing exposure to parasite and in some cases subsequent environmental contamination with parasites; and 9) parasite evolution [27] - likely to be detected first among protozoans. For people dependent to some extent on wildlife, as many northerners are, parasites may be one of the means by which climate change results in shifts in the availability and quality, or perceived quality, of their food and other key products (e.g. hides and pelts) of wildlife origin, and in the role of wildlife in their cultural and economic wellbeing and in the sustainability of northern communities.

For parasites, some potential boundary shifts are similar to those for hosts. For example, as distributions and faunal structures for hosts shift, so too will those for parasites. In some ecosystems, as a result of host switching, both immigrant (or invasive) and endemic hosts may experience new parasites, and these may be especially pathogenic for naïve hosts and may result in emergent or resurgent diseases. Shifts in parasite faunal structure may also result from altered trophic linkages, and the levels of nutrition, health and wellbeing of hosts will influence their susceptibility to parasites and other diseases and may lead to shifts in the role of parasites in ecosystem dynamics. Outside their mammalian and avian hosts, many parasites have life cycle stages in the environment or in ectothermic intermediate hosts and vectors that are exposed directly to climate. Key potential boundary shifts here are in parasite survival and 
development rates [12] and, for some species, in amplification rates for parasites developing in ectothermic hosts [11]. If warming from climate change enhances these rates, lengthens the summers vital for the transmission of many northern parasites, and shortens and softens the winters then, simplistically, more infective stages of parasites could be available sooner and the transmission period could be extended. In some instances, these shifts have the potential to generate greater parasite abundance in the definitive hosts and to increase their health impacts.

\section{Some case studies}

Despite our currently relatively limited understanding of the ecology of host-parasite assemblages in the Arctic and the North, it is possible to speculate how some might be influenced by climate change. Although evidence transforming this speculation to certainty remains sparse, it is important to consider these issues and especially to identify potential high-risk scenarios for the emergence of significant parasitic disease in people and in wildlife.

\section{Trichostrongyles of Ungulates}

Trichostrongyles (e.g. Ostertagia gruehneri andTeladorTeladorsagia boreoarcticus) are non-zoonotic nematodes that as adults parasitise the abomasum or intestines. They have direct life cycles involving the development of eggs deposited in the feces to free-living, infective larvae in the environment. Infection of ungulate hosts is by ingestion of these larvae. Climate change, as well as its positive or negative effects on the hosts, may shift patterns of development for the parasites' free-living stages. For example, assuming adequate moisture, longer, warmer summers may increase survival and development rates for the free-living stages leading perhaps to shorter generation times and to greater abundance and increased longevity for infective larvae in the environment. This in turn may increase the infection pressure and parasite loads for hosts and lead to greater adverse impacts on host health (e.g. weight loss and reduced conception rates) $[28,29]$ and, for species important as food for northerners, on human health. In addition, altered summer transmission dynamics and fall climate may shift patterns of larval inhibition in the gastro-intestinal mucosa, an important mechanism for overwinter survival by some trichostrongyles in other areas of the world. A useful preliminary glimpse of the links between climate change and altered ecology for trichostrongyles can be derived from basic information about pre-patent periods and the relationships between environmental temperatures and larval survival and development rates as determined in the laboratory and in the field. Data are plentiful on these aspects of trichostrongyles of domestic animals in several areas of the world [12], but caution is required when attempting to extrapolate these data to the species of parasites infecting free-ranging hosts, particularly in the Arctic and the North.

\section{Protostrongylids of Ungulates}

Protostrongylid nematodes (e.g. Umingmakstrongylus pallikuukensis, Parelaphostrongylus odocoiei and $P$. andersoni) are non-zoonotic and live as adults in the airways, lung parenchyma or skeletal musculature. Their life cycles are indirect, involving development of firststage larvae deposited in feces to infective larvae in gastropod intermediate hosts. Infection of ungulates is by ingestion of infected gastropods or of infective larvae spontaneously emerged from the gastropods.

The life cycle stages of these parasites outside the hosts have vulnerabilities to climate change generally similar to those of the trichostrongyles but it is possible that gastropod mobility and avoidance of extreme habitat conditions may protect the larvae from some of the effects of a changed climate [30].

For $U$. pallikuukensis, an empirical model derived from laboratory and field studies demonstrated that warming in the North probably has already shortened larval development times in gastropods and shifted transmission dynamics from a two-year to a one-year adult-to-adult cycle [31]. A similar model for P. odocoilei indicated that temperature constraints affecting larval development rates in gastropods may define the northern limits of the parasite's distribution, and that warming may remove these and lead to an expanded parasite distribution [10]. Also, for $U$. pallikuukensis, attempted experimental infections indicated that thinhorn sheep, potentially newly sympatric with muskoxen as a result of shifts in host geographic distributions perhaps associated with climate change, are not susceptible to the parasite [32].

\section{Trichinella nativa}

Trichinella is a genus of zoonotic nematode containing species that infect a range of vertebrates, including people, in many parts of the world. Trichinella nativa is the primary northern species. Adult Trichinella live in the small intestine, and the larvae produced by the female parasites migrate to skeletal muscle and sometimes other tissues. These larvae are the parasite's infective stage and transmission is by carnivorism, including feeding on carrion. In the North many host species are infected, and of special concern are those consumed by people, especially polar and black bear, walrus, and seal. Other than in carrion, life cycle stages of Trichinella are not exposed to the environment and any effects of climate change are likely to result primarily from shifts 
in host faunal structure and trophic linkages [26]. Outside the North, the ecology of Trichinella may be modified by climate-induced shifts in contacts between wildlife and domestic animals, and perhaps through behavioural shifts in the utilization of infected hosts as food for people.

\section{Cryptosporidium and Giardia}

Among the several species and genotypes currently established for each of these two genera of protozoans some are zoonotic and infect a range of hosts but most seem restricted to a single host species [33]. Although some species/genotypes are shared between people and domestic animals, the significance of wildlife as sources of human infections, and of people as a source of the parasites for wildlife, remain uncertain and unexplored. Both parasites live primarily in the small intestine and the life cycles are direct. Infection is by ingestion of infective oocysts (Cryptosporidium) or cysts (Giardia) from the environment or from contaminated food or water. Climate change has the potential to alter survival rates for the cysts and oocysts (which are infective when voided by the hosts) and, because both parasites are found in surface water, shifts in local and regional hydrology may alter parasite distributions and the risks of human and animal exposure. In human settlements altered patterns of precipitation and extreme climatic events may disrupt the integrity of the infrastructure, particularly water supplies and sewage disposal, increasing the risk of human infection. In addition, these elements of the climate change may result in increased run-off and contamination of water with animal feces, and increased risk of zoonotic transmission.

\section{Priorities for action}

For people, domestic animals and especially wildlife, in many situations around the world it is difficult to identify all the causes of detectable shifts in disease occurrence and, correctly, efforts are directed principally at mitigation of the disease and at effective control. Additionally, for all host groups, it may be difficult to tease parasites from among other potential contributors to disease, and to determine the role of climate in shifts in disease ecology and host health [34]. For wildlife, the detection of these shifts may also be hampered by a lack of baseline data for the occurrence and significance of pathogens and diseases. In exploring climate change as a cause of new patterns of disease, however, much can be learned from the many data-derived relationships between key climatic factors and host, parasite and disease ecology, and the integration of these with projections for climate change trajectories. This capability, coupled with an integrative, multidisciplinary and ecological approach, makes possible the identification of parasitic infections and diseases likely to be particularly susceptible to climate change and, with adjustments for regional variations, the exploration of some of the possible consequences of accelerating climate change for the occurrence of these diseases and for animal and human health. This is a very urgent need, and without such an attempt to anticipate the possible, society is likely to be a more or less impotent spectator to the certainty of continual ecological calamities.

\section{Author details}

${ }^{1}$ Department of Veterinary Microbiology, Western College of Veterinary Medicine, University of Saskatchewan, Saskatoon, Saskatchewan S7N 5B4, Canada. ${ }^{2}$ National Parasite Collection, Agricultural Research Service, United States Department of Agriculture, Beltsville, Maryland 20705, USA.

${ }^{3}$ Department of Ecosystem and Public Health, Faculty of Veterinary Medicine, University of Calgary, Calgary, Alberta T2N 4N1, Canada.

Published: 13 October 2010

\section{References}

1. IPCC: Summary for Policymakers. Climate Change 2007: The Physical Science Basis. Contribution of Working Group I to the Fourth Assessment Report of the Intergovernmental Panel on Climate Change Cambridge University Press, Cambridge, United Kingdom and New York, NY, USASolomon S, Qin D, Manning M, Chen Z, Marquis M, Averyt KB, Tignor M, Miller HL 2007.

2. Patz JA, Graczyk TK, Geller N, Vittor AY: Effects of environmental change on emerging parasitic diseases. Int. J. Parasitol 2000, 30:1395-1405.

3. Folke C, Carpenter S, Walker B, Scheffer M, Elmqvist, Gunderson L, Holling CS: Regime shifts, resilience, and biodiversity in ecosystem management. Ann. Rev. Ecol. Evol. Syst 2004, 35:557-581.

4. Moore SE, Huntington HP: Arctic marine mammals and climate change: impacts and resilience. Ecol. Applic 2008, 18(Supplement):S157-S165.

5. Sumilo D, Asokliene L, Bormane A, Vasilenko V, Golovljova I, Randolph SE: Climate change cannot explain the upsurge of tick-borne encephalitis in the Baltics. PLOS ONE 2007, 2:e500.

6. Sumilo D, Bormane A, Asokliene L, Vasilenko V, Golovljova I, Avsic-Zupanc T, Hubalek Z, Randolph SE: Socio-economic factors in the differential upsurge of tick-borne encephalitis in Central and Eastern Europe. Rev. Med. Virol 2008, 18:81-95.

7. Cardenas R, Sandoval CM, Rodriguez-Morales AJ, Franco-Paredes C: Impact of climate variability in the occurrence of leishmaniasis in northeastern Colombia. Am. J. Trop. Med. Hyg 2006, 75:273-277.

8. Curriero FC, Patz JA, Rose JB, Lele S: The association between extreme precipitation and waterborne disease outbreaks in the United States. Am. J. Publ. HIth 2001, 91:1194-1199.

9. Ogden NH, Maarouf A, Barker IK, Bigras-Poulin M, Lindsay LR, Morshed MG, O'Callaghan CJ, Ramay F, Waltner-Toews D, Charron DF: Climate change and the potential for range expansion of the Lyme disease vector Ixodes scapularis in Canada. Int. J. Parasitol 2006, 36:63-70.

10. Jenkins EJ, Veitch AM, Kutz SJ, Hoberg EP, Polley L: Climate change and the epidemiology of protostrongylid nematodes in northern ecosystems: Parelaphostrongylus odocoilei and Protostrongylus stilesi in Dall's sheep (Ovis d. dalli). Parasitology 2006, 132:387-401.

11. Poulin R: Global warming and temperature-mediated increases in cercarial emergence in trematode parasites. Parasitology 2006, 132:143-151.

12. O'Connor $\amalg$, Walkden-Brown SW, Kahn LP: Ecology of the free-living stages of major trichostrongylid parasites of sheep. Vet. Parasitol 2006 142:1-15.

13. Van Dijk J, Morgan ER: The influence of temperature on the development, hatching and survival of Nematodirus battus larvae. Parasitology 2008, 135:269.

14. Ollerenshaw CB, Smith LP: Meteorological factors and forecasts of helminthic disease. Adv. Parasitol 1969, 7:283-323.

15. Cox J, Abeku TA: Early warning systems for malaria in Africa: from blueprint to practice. Trends Parasitol 2007, 23:243-246. 
16. Fuentes MV, Sainz-Elipe S, Nieto P, Malone JB, Mas-Coma S: Geographical Information Systems risk assessment models for zoonotic fasciolosis in the South American Andes region. Parassitologia (Roma) 2005, 47:51-156.

17. Chaves LF, Pascaul M: Climate cycles and forecasts of cutaneous leishmaniasis, a non-stationary vector-borne disease. PLoS Medicine 2006, 3:1320-1327.

18. Polley L: Navigating parasite webs and parasite flows: emerging and reemerging parasitic zoonoses of wildlife origin. Int. J. Parasitol 2005, 35:1279-1294

19. Hoberg EP, Polley L, Jenkins EJ, Kutz SJ, Veitch AM, Elkin BT: Integrated approaches and empirical models for the investigation of parasitic diseases in northern wildlife. Emerg. Inf. Dis 2008, 14:10-17.

20. Kutz SJ, Asmundsson I, Hoberg EP, Appleyard GD, Jenkins EJ, Beckman K, Branigan M, Butler L, Chilton NB, Cooley D, Elkin B, Huby-Chilton F, Johnson D, Kuchboev A, Nagy J, Oakley M, Popko R, Scheer A, Simard M, Veitch A: Serendipitous discovery of a novel protostrongylid (Nematoda: Metastrongyloidea) in caribou, muskoxen, and moose from high latitudes of North America based on DNA sequence comparisons. Can. J. Zool. 2007, 85:1143-1156.

21. Furgal C, Seguin J: Climate change, health, and vulnerability in Canadian northern aboriginal communities. Envir. Health Perspect 2006, 114:1964-1970.

22. Anisimov OA, Vaughan DG, Callaghan TV, Furgal C, Marchant $H$, Prowse TD, Vilhjálmsson H, Walsh JE: Polar regions (Arctic and Antarctic). Climate Change 2007: Impacts, Adaptation and Vulnerability. Contribution of Working Group II to the Fourth Assessment Report of the Intergovernmental Panel on Climate Change Cambridge University Press, CambridgeParry ML, Canziani OF, Palutikof JP, van der Linden PJ, Hanson CE 2007, 653-685.

23. Root TL, Price JT, Hall KR, Schneider SH, Rosenzweig C, Pounds JA: Fingerprints of global warming on wild animals and plants. Nature 2004, 421:57-60.

24. Brooks DR, Hoberg EP: How will global climate change affect parasitehost assemblages? Trends Parasitol 2007, 23:571-574.

25. Hoberg EP, Polley L, Jenkins EJ, Kutz SJ: Pathogens of domestic and freeranging ungulates: global climate change in temperate to boreal latitudes in North America. Rev Sci Tech 2008, 27:511-528.

26. Rausch RL, George JC, Brower HK: Effect of climate warming on the Pacific walrus, and potential modification of its helminth fauna. J. Parasitol 2007, 93:1247-1251.

27. Lebarbenchon C, Brown SP, Poulin R, Gauthier-Clerc M, Thomas F: Evolution of pathogens in a man-made world. Mol. Ecol 2008, 17:475-484.

28. Albon SD, Stien A, Irvine RJ, Langvatn R, Ropstad E, Halvorsen O: The role of parasites in the dynamics of a reindeer population. Proc. R. Soc. Lond. B 2002, 269:1625-1632.

29. Stien A, Irvine RJ, Ropstad E, Halvorsen O, Langvatn R, Albon SD: The impact of gastrointestinal nematodes on wild reindeer: experimental and cross-sectional studies. J. Anim. Ecol 2002, 71:937-945.

30. Kutz SJ, Hoberg EP, Nishi J, Polley L: Development of the muskox lungworm, Umingmakstrongylus pallikuukensis (Protostrongylidae) in gastropods in the Arctic. Can. J. Zool 2002, 80:1977-1985.

31. Kutz SJ, Hoberg EP, Polley L, Jenkins EJ: Global warming is changing the dynamics of arctic host-parasite systems. Proc. R. Soc. Lond. B 2005, 272:2571-2576.

32. Kutz S, Garde E, Veitch A, Nagy J, Ghandi F, Polley L: Muskox lungworm (Umingmakstrongylus pallikuukensis) does not establish in experimentally exposed thinhorn sheep (Ovis dalli). J. Wildl. Dis 2004, 40:197-204.

33. Hunter PR, Thompson RCA: The zoonotic transmission of Giardia and Cryptosporidium. Int. J. Parasitol 2005, 35:1181-1190.

34. Cattadori IM, Haydon DT, Hudson PJ: Parasites and climate synchronize red grouse populations. Nature 2005, 433:737-741.

\section{Submit your next manuscript to BioMed Central and take full advantage of:}

- Convenient online submission

- Thorough peer review

- No space constraints or color figure charges

- Immediate publication on acceptance

- Inclusion in PubMed, CAS, Scopus and Google Scholar

- Research which is freely available for redistribution

Submit your manuscript at www.biomedcentral.com/submit
Biomed Central 